\title{
Dali's Mystic Elements and their Meaning
}

\section{Ticiana Dine}

\section{Doi:10.5901/ajis.2015.v4n3s1p269}

\section{Abstract}

The entire study is based on the connection between the symbolisms that Dali uses in his artworks as well as what Freud uses as scientific terminology in his research studies about the experiences of his patients. How Freud sees and analyzes them mainly when drawers and other elements similar to those emptied and filled are present in humans neurosis, or paranoids and how Dali makes interweaving precisely with this element into his surreal works by analyzing them as symbols which represent emptiness of soul but at the same time represents not only a need but why not also a sexual femininity through this symbol. What is taken for study is duplication and comparison between a doctor and an artist who takes the role of a doctor making besides a symbolic and artistic analysis but first of all also an analytical context. If Freud makes this study on patients and their similar experiences, Dali does this with its audience. This type of comparison and duplication in terms of perception or the way the patients dream or how understand and perceive it the observers in an art gallery, it makes me rise an analysis point. I did it comparing the two prominent figures very much internationally recognized whom were far and near to each other.

Keywords: mystic, erotic connotations, Freud's symbolic, etc.

"Theretofore the surrealists that in appearance had been selected me out as their saint, seemed to me some crazy people 100 percent. This young Spaniard, with fanatic's staring eyes and his inevitable mastery had prepossessed me to reconsider my opinion. We are talking about someone with serious psychological problems." Sigmund Freud.

Into artworks of Dalí we may see such elements as twigs, flies, ants, butterflies, protruding feet and bodies, drawers, holding watches and crutches. Inside his works there are sexual sensations, where between the chaotic images that apparently look like a dream filled with sensation and sexual symbols, many of the symbols of Dalí are beyond simply the artistic and surrealist ones or mysticism as well. Many of the elements into the works of Dalí are filled with oneiric images and symbols wherein its interpretation is based on oneiric Freudian interpretation. Based on Freudian theories the symbols and elements found into the dreams of his patients, Freud realized that many of the symptoms or conditions of paranoia came as sexually repressed state, which constantly harassed the human psyche.
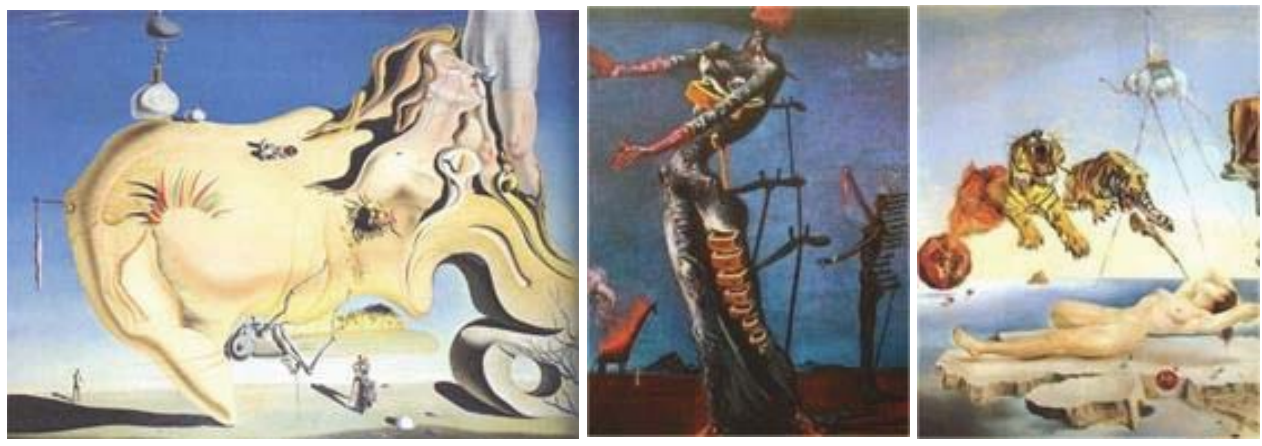

Figure 1. The Great Masturbator

Figure 2. The Burning Giraffe

Figure 3. Dream Caused by the Flight of a Bee Around a Pomegranate a Second Before Awakening

These conditions had created sensations and temptations and emotional oscillations and behavior which made often patients of Freud to be inclusive in a position where they can be helped just by hearing them always that elements by which they were scared of often were those symbols and elements which have a sexual explanation such rifles, 
pomegranates, tigers, extended twigs and sticks, scales, drawers, etc. These psychological and sexual elements are intertwined, treated and studied throughout his life by Doctor Sigmund Freud. Very much so these elements and symbols will be found into the works of Dalí in order to be interpreted in the same form as would do Freud with his patients. "A true artist understands how to exceed his dreams of the day ... to make them possible for others by sharing with them his satisfaction." Sigmund Freud

\section{Oneiric Elements and Symbols}

In the above works, we may see some symbols which are characteristic not only of Dalí but are also related to the oneiric interpretation. I'll not analyze these artworks but I will take them as examples to identify elements and symbols, which are translated by Freud in a sexual context into a dream. First of all I must say that these elements which I have analyzed and seen from a completely different interpretative perspective associated with mystical symbols, however in this study I will make a connection between oneiric of Freud and symbols of Dalí in these works, always not forgetting neither inspiration nor influence that interpretation of dreams by Freud influenced on Surrealist artist as Dalí. In a large part of the works of Dalí we may see how the symbols, which are taken as references by Freud to review and analyze his neurotic patients or cramps of phobias and feelings which make the people reclusive, Dalí treats them like elements, which can be studied by a magnifying glass in a symbolic and sexual context, just like Freud emphasized the analysis of these symbols. In the relationship between Freudian oneiric analysis and symbolic analysis of Dalí there is a very radical difference. I would say that although Freud in the presentation of drawers sees spiritual state or erotic symbols as well as prolonged sticks and elements presenting sexual need, however Dalí will vouchsafe another interpretation to drawers, which will be viewed by him in a more extensive aspect by representing not just the sexual but even the spiritual fulfillment as well as sticks or crutches, through which would represent a need for support and uplift. In this context, his works became more artistic. Although Dalí asked, just like his contemporaries who were based on oneiric Freudian interpretation and much more Dalí who claims that Freud is my guru, we can say that the oneiric Freudian interpretation is grown bare completely under a context from sexuality to the symbolic one and now and then to the surreal, not necessarily seeking a real objective interpretation. When Dalí talks about Paranoid-Critical Method he excludes the possibility of an oneiric Freudian interpretation because there we may see another interpretative form which again is not linked to the symbolism, but with a form of observing the images and forms under an imaginary, illusory or completely hallucinatory self-induced paranoid method, not as neurotic part nor distortion of reality unconsciously. Freud writes in the book On Dreams that meaning of a dream can be divulge by the recognition of symbols which seem to be translate into a universal language among people than the same communicative language of our own. Freud writes that we may derive based on the ancient peoples who did the same interpretative connection between oneiric symbols and symbols themselves in general. (Sigmund Freud- On dreams -publishing house "Fan Noli", Tirana, 1997, translated from German into Albanian - by editor Rexhep Hida, pag.89) Freud goes on to make a connection, as in another study I have pointed to interpretation of mystical symbols, between symbols which have present the Knave, Queen and King. Freud makes a connection between these figures by interpreting them in the same way they have been interpreted into a dream as well as in Tarot cards where Dalí had an impact on symbols, which are represented by him in his works too. Freud writes that figures like King and Queen are figures which mean parents, rooms are representing women, entrances and exits are representing physical holes. Most of the dream symbols serve to represent people, body parts and activities marked with erotic interest; Freud says that genital parts are presented by strange symbols and different facilities, he features such thing as guns, sticks, tree trunks, those symbols that replace male genitals to undergo a metamorphosis which need an interpretation that is not always easily comprehensible for us. Meanwhile Freud also mentions cabinets, ovens, drawers, cars, which replace the female body into a dream. Freud says that a whole range of symbols are bisexual, according to the context they can be taken for female or male genitalia. (Sigmund Freud- On dreams - publishing house "Fan Noli", Tirana, 1997, translated from German into Albanian - by editor Rexhep Hida, pag .90-91) So a dream, writes Freud, can present symbolically the erection. Freud goes on to explain the rank symbols that resemble sexual exigency as well as female genital organ and furthermore male organ. Freud ranked umbrellas, sticks, trees, pencils, spears, swords, rifles, pistols, dams, hammers, pending light bulbs, sliding, skating, sweets, peaches, table and book, ties, hats, fruit, mountains, rocks, etc. (Sigmund Freud - Human Sexual Life - publishing house "Fan Noli", Tirana, 1997, translated from German into Albanian - by editor Rexhep Hida Chapter 2. Developing libido and sexual body, p. 91, Dalí, 1981/1942, p.179 by Sigmund Freud - publishing house "Fan Noli", Tirana, 1997, translated from German into Albanian - by editor Rexhep Hida.- The Symbolism of the dream p. 38-43) Freud studied neurotic cases of his patients, sexual traumas and Phobias, events recorded in the past, which had undergone with time a distortion of the event by turning it into a dream 
filled with symbols and figures, a state of fear that persecute the dreamer. Freud studied the symbolism and interpretation of these images in order to enter into unconsciousness as well as into oneiric state through hypnosis, which was the more appropriate way to give an indication of the unconscious, which is the darkest background of human being. Dalí in turn used symbolism to interpret a distorted reality, which came from the dreams but not from the anxieties and neurotic conditions, phobias and events which troubled psyche of the observer. I say observer because Dalí was precisely estimated by the observer. Dalí attempted that sexual interpretation of these symbols to be represented into his works as symbols that must be interpreted by the recipient under the Freudian sexual symbolic language. I think that here Dalí fails to transmit it properly because the receiver has never proper knowledge to make a symbolic and psychoanalytical interpretation and moreover the receiver has in front of himself a picture, which he has to see under surreal, symbolic, artistic, or oneiric Freudian symbolic complexion. Meanwhile we shall not forget the theory about Paranoid-Critical Method by which the observer makes the reality and work. Dalí spoke about symbolism from many different angles and this I believe since then and even now confuses the observer in interpreting or understanding the works of Dalí. While my skepticism stops off also on transmitting symbolic forms that Dalí raises with audience treating it often as a stage or condition of paranoid hypnosis. If Freud set up the system of analyses of these images because he wanted to remove from subject the oneiric repeated situations that lead to neurosis, Dalí does the exact opposite by setting up a confused system of images and symbols and expecting that this paranoid and complicated system to be decipher by observer in the most objective way, by not proposing any observation's spot that these symbols should be subject to decipherable analysis. Finally, the difference between oneiric of surrealism and Dali's contemporaries artists was that they used symbolism in their works as a state in which the work itself did not need to be interpreted objectively because it represented a chaotic symbolic situation by making it more artistic and not going further more beyond it. For Dalí a dream it is a symbolic background, which is seen both under artistic, surreal, paranormal and mystical complexions.

\section{References}

Salvador Dali - Interpretation of Dreams a radical discovery of my life (Dali, 1981/1942, p. 179)

Sigmund Freud -The Interpretation of Dreams - the publishing house 'Fan Noli', Tirana, 2010, translated from German into Albanian by Haxhire Luli) http://www.dali-interart.be/pdf/dali_symbols.pdf Sigmund Freud - Human Sexual Life-The publishing house "Fan Noli" Tirana, 1997, translated from German into Albanian by Rexhep Hida, Chapter 2.

Sigmund Freud - Developing libido and sexual body -publishing house "Fan Noli" Tirana, 1997, translated from German into Albanian by Rexhep Hida, chapter 2. The symbolism of the dream p. 38-43)

Sigmund Freud- On dreams -publishing house "Fan Noli", Tirana, 1997, translated from German into Albanian - by Editor Rexhep Hida, pag.89.

Sigmund Freud- On dreams -publishing house "Fan Noli", Tirana, 1997, translated from German into Albanian - by Editor Rexhep Hida, pag. $90-91$

www.dali-interart.be

dali-interart.be 